\title{
KARAKTERISTIK MORTAR POLIMER EPOXY RESIN DENGAN FIBERGLASS
}

\author{
Bambang Utomo'), Siti Aisyah Nurjannah ${ }^{2 *}$, dan Saloma ${ }^{2)}$ \\ 1) Program Studi Magister Teknik Sipil, Fakultas Teknik, Universitas Sriwijaya, Palembang, Sumsel \\ 2)Jurusan Teknik Sipil dan Perencanaan, Fakultas Teknik, Universitas Sriwijaya, Ogan Ilir, Sumsel
}

\begin{abstract}
Nowadays, the developments of technology in construction are progressing very rapidly, one of which is mortar without using cement material. This encourages the development of concrete and mortar technology so that it can be widely used to repair structural or non-structural damages. In these conditions, a binder is needed in the form of an epoxy resin polymer with added fiberglass to get a strong material result in a short time. A mixture of $75 \%$ sand and $25 \%$ epoxy resin from the volume of the test object resulted a mortar compressive strength of $35.50 \mathrm{MPa}$ with a specific gravity of $1.505 \mathrm{~kg} / \mathrm{m}^{3}$. The results showed that the variation of the compressive strength of the epoxy resin mortar without fiber was higher than the variation with fiberglass. This was due to the addition of fiberglass reducing the composition of the percentage of epoxy resin which results in reduced bonding power in the mixture. The flexural strength of a mortar with variations using fiberglass was $8 \mathrm{MPa}$ and showed the best performance, although the difference was not too far from the variation without fiberglass. This was because the addition of fiberglass can reduce cracks, so that the fibers can bind well. The tests had been carried out including tests of the compressive strength, flexural strength, and Scanning Electron Microscope (SEM).
\end{abstract}

Key Words: Compressive strength, epoxy resin, fiberglass, flexural strength, polymer.

\section{PENDAhuluan}

Beton dalam bidang konstruksi memiliki peran penting sebagai salah satu material struktur yang sampai saat ini banyak digunakan sebagai bahan bangunan. Beberapa wilayah di Indonesia berada pada jalur lempeng tektonik. Hal ini mendorong perkembangan teknologi beton digunakan secara luas untuk memperbaiki kerusakan bangunan akibat gempa ataupun beban lainnya. Kerusakan struktur bangunan dapat juga terjadi akibat desain yang kurang akurat, sehingga kekuatan struktur kurang dari kebutuhan. Pada kondisi tersebut, dalam proses pembuatan beton, diperlukan penambahan bahan pengikat berupa polimer resin dengan tipe accelerator untuk mendapatkan hasil yang lebih optimal dan mempercepat pencapaian mutu mortar menjadi kurang dari 28 hari. Salah satu bahan material yang memiliki reaksi untuk menambah daya tahan yang kuat jika terkena epoxy resin yaitu fiberglass. Jagarapu, dkk. (2016) Keuntungan menggunakan resin polimerik adalah memiliki kekuatan mekanis yang tinggi, durabilitas tinggi, dan ketahanan terhadap serangan kimia.

Penelitian ini bertujuan untuk mengetahui dan menganalisis komposisi campuran dan pengaruh penambahan fiberglass terhadap sifat fisik dan mekanik mortar polimer epoxy resin. Pengujian yang dilakukan meliputi pengujian kuat tekan, pengujian kuat lentur, dan Scanning Electron Microscope (SEM).

Juanda, dkk. (2019) bahwa beton merupakan bahan konstruksi yang paling banyak digunakan karena produksinya sesuai dengan rencana kuat tekan, memiliki kemampuan untuk menahan suhu tinggi, dan bahan produksinya yang mudah didapatkan.

Gowri dan Angeline (2013) bahwa perkembangan teknologi beton saat ini menuju peningkatan daya tahan beton untuk memenuhi tuntutan dunia konstruksi modern dengan biaya rendah. Penambahan serat merupakan salah satu metode baru pada beton. Parameter kekuatan beton seperti kuat tekan dan kuat lentur dipelajari dengan memvariasikan persentase serat dari $0,025 \%$ sampai dengan $0,075 \%$ dari berat beton.

Ravikumar, dkk. (2015) hasil penelitian bahwa peningkatan yang signifikan karena penggunaan serat dalam mortar untuk meningkatkan kinerja, antara lain kuat tarik dan daktilitas. Mortar serat juga digunakan dalam perkuatan struktur yang ada. Di antara berbagai jenis serat yang tersedia saat ini, 
serat fiberglass merupakan salah satu hasil pengembangan terbaru di bidang teknologi beton.

Deshmukh, dkk. (2012) bahwa beton adalah bahan bangunan yang lemah dalam menahan tegangan, mudah retak akibat sifat getas, serta mengalami susut akibat pengeringan dan sejenisnya. Beton yang memiliki kekuatan tarik rendah menghasilkan daktilitas terbatas dan ketahanan retakyang rendah.

Pimplikar dan Shakor (2011) melakukan percobaan bahan beton bertulang fiberglass dari matriks semen yang terdiri dari semen, pasir, air dan bahan tambahan, dengan serat berukuran pendek. Hasil penelitian yang dilakukan adalah bahwa beton yang terdiri dari semen bertulang dengan penambahan fiberglass memiliki pengaruh peningkatan kinerja pada hasil pengujian.

Kumar dan Venkatesh (2018) melakukan penelitian mengenai mortar dengan serat fiberglass sebanyak $0,5 \%, 1 \%, 2 \%$, dan $3 \%$, serta mengandung semen sebagai campuran. Hasil penelitiannya adalah bahwa penambahan fiberglass ke dalam beton dapat secara signifikan meningkatkan kuat tekan, kuat lentur, dan kuat tarik belah pada beton.

Bowo, dkk. (2020) melakukan penambahan polimer ke dalam beton tanpa semen dengan tujuan untuk meningkatkan sifat beton dan mempersingkat waktu proses pembuatan. Untuk meningkatkan daya tahan struktur beton, terdapat banyak penelitian telah dilakukan dalam beberapa dekade terakhir pada modifikasi polimer sebagai salah satu metode yang paling efektif untuk meningkatkan kinerja beton.

Berdasarkan uraian latar belakang diatas, maka bisa diambil suatu rumusan masalah sebagai berikut:

a. Bagaimana menentukan komposisi campuran untuk menghasilkan mortar polimer dengan karakteristik yang baik?

b. Bagaimana pengaruh dalam penambahan fiberglass terhadap sifat fisik dan mekanik mortar polimer dan mikrostruktur?

Berdasarkan rumusan masalah di atas, maka tujuan yang ingin dicapai dari penelitian ini adalah sebagai berikut:

a. Menentukan komposisi campuran yang optimum pada mortar polimer.

b. Mengetahui dan menganalisis pengaruh variasi penambahan fiberglass terhadap sifat fisik dan mekanik mortar polimer.

Untuk membatasi ruang lingkup penelitian, maka diperlukan batasan masalah sebagai berikut:

a. Perbandingan epoxy resin dan agregat halus adalah $15 \%$, 20\%, dan $25 \%$. b. Penggunaan epoxy resin dengan rasio perbandingan epoxy dan hardener 1:0,5.

c. Penggunaan fiberglass $3 \%$ subtitusi pada epoxy.

d. Pengujian mortar segar meliputi setting time berdasarkan standar ASTM C 191 dan slump flow berdasarkan standar ASTM C 1437.

e. Pengujian karakteristik mortar polimer meliputi kuat tekan, kuat lentur, SEM, dan Penelitian berdasarkan ASTM (American Standard Testing and Material).

\section{METODOLOGI}

Penelitian dibagi menjadi lima tahap. Pada tahap awal, terdapat proses pencampuran epoxy resin dan pasir, lalu diaduk sampai merata dan berubah warna menjadi kekuningan. Rasio perbandingan campuran material ini berdasarkan volume. Kadar epoxy resin variasi terbesar dalam penelitian ini adalah sebesar $25 \%$ dengan tujuan untuk mendapatkan kekuatan maksimal dengan perbandingan antara jumlah pasir dan epoxy resin yaitu 75\%:25\% dari volume total mortar. Pencampuran resin dan pasir dengan kondisi kering udara. Beberapa variasi yang digunakan yaitu kadar epoxy resin sebanyak $15 \%, 20 \%$, dan $25 \%$ terhadap volume benda uji. Epoxy resin yang digunakan terdiri dari dua macam, yaitu epoxy resin jenis pasta dan epoxy resin jenis cairan. Fiberglass yang digunakan adalah chopped strand mat (CSM) yang dikenal sebagai jenis serat dengan anyaman dan diproduksi secara acak ke berbagai arah dan tidak beraturan.

Pengujian berat jenis dan kuat tekan menggunakan cetakan benda uji berbentuk kubus dengan ukuran $50 \mathrm{~mm}$ x $50 \mathrm{~mm}$ x $50 \mathrm{~mm}$, pengujian kuat lentur berbentuk balok dengan ukuran $150 \mathrm{~mm}$ x $150 \mathrm{~mm}$ x $600 \mathrm{~mm}$, pengujian modulus elastisitas berdiameter $150 \mathrm{~mm}$ x $300 \mathrm{~mm}$ yang dilakukan setiap umur 7 hari, 14 hari dan 28 hari.

Komposisi beton dalam penelitian ini berdasarkan pada penelitian yang dilakukan oleh Yemam, dkk. (2017). Perbandingan massa epoxy dan hardener adalah 2:1 Juanda, dkk. (2019). Pada Tabel 1 dan Tabel 2 presentase $75 \%, 80 \%$, dan $85 \%$. Untuk melakukan studi perbandingan, maka presentase pasir, semen, dan air dalam komposisi beton normal pada Tabel 3 tediri dari semen hardener, dan fiber.

Tabel 1. Komposisi campuran mortar polymer (MP)

\begin{tabular}{cccccc}
\hline \multicolumn{2}{c}{ Pasir } & \multicolumn{2}{c}{ Epoxy } & \multicolumn{2}{c}{ Hardener } \\
\hline$(\%)$ & (gram) & $(\%)$ & gram) & $(\%)$ & (gram) \\
\hline MP-75 & 1.050 & 16,67 & 195 & 8,33 & 97,5 \\
MP-80 & 1.120 & 13,33 & 156 & 6,67 & 78,0 \\
MP-85 & 1.190 & 10,00 & 117 & 5,00 & 58,4
\end{tabular}


Cantilever $\mid$ Volume: 10 Nomor: 2 Oktober 2021 ISSN: 1907-4247 (Print) $\mid$ ISSN: 2477-4863 (Online) | Website: http://cantilever.id Bambang Utomo, dkk. | Karakteristik Mortar Polimer Epoxy Resin Dengan Fiberglass

\begin{tabular}{cccccccc}
\multicolumn{3}{c}{ Tabel 2. Komposisi campuran mortar polymer fiber (MPF) } \\
\hline \multicolumn{2}{c}{ Pasir } & \multicolumn{2}{c}{ Epoxy } & \multicolumn{2}{c}{ Hardener } & \multicolumn{2}{c}{ Fiber } \\
\hline$(\%)$ & (gram) & $(\%)$ & gram) & $(\%)$ & (gram) & $(\%)$ & (gram) \\
\hline 75 & 1.050 & 15,17 & 175 & 6,83 & 79,5 & 3 & 79 \\
80 & 1.120 & 11,83 & 140 & 5,17 & 57,5 & 3 & 79 \\
85 & 1.190 & 8,50 & 94 & 3,50 & 41,0 & 3 & 79
\end{tabular}

Tabel 3. Komposisi campuran mortar semen (MS)

\begin{tabular}{cccccc}
\hline \multicolumn{2}{c}{ Pasir } & \multicolumn{2}{c}{ Semen } & \multicolumn{2}{c}{ Air } \\
\hline$(\%)$ & $($ gram $)$ & $(\%)$ & gram $)$ & $(\%)$ & $($ gram $)$ \\
\hline 75 & 1.050 & 16,67 & 467 & 8,33 & 233 \\
80 & 1.120 & 13,33 & 373 & 6,67 & 186 \\
85 & 1.190 & 10,00 & 280 & 5.00 & 140 \\
\hline
\end{tabular}

\section{HASIL DAN PEMBAHASAN \\ Waktu Ikat (Setting Time)}

Pengukuran waktu ikat pada pasta dilakukan dengan menggunakan jarum vicat. Data waktu pengikatan terdiri dari waktu ikat awal (initial setting time) dan waktu ikat akhir (final setting time) yang diperlihatkan pada Gambar 1. Waktu ikat awal dan akhir tercepat terdapat pada campuran MS- $25 \%$, yaitu selama 50 dan 120 menit, sedangkan waktu ikat awal dan akhir terlama terdapat pada campuran MPF-15\% yaitu 90 dan 165 menit, dengan penambahan fiberglass memperlambat hasil uji setting time.

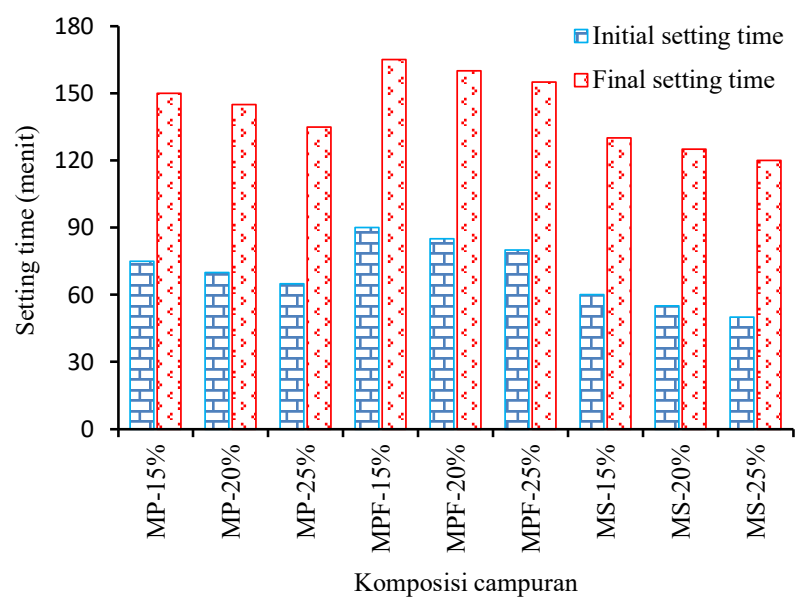

Gambar 1. Setting time mortar polimer epoxy resin

\section{Berat Jenis}

Hasil pengujian berat jenis mortar polymer epoxy resin disajikan pada Gambar 2. Target berat jenis (density) yang dicapai berkisar antara 1.200-1.800 $\mathrm{kg} / \mathrm{m}^{3}$. Berat jenis terendah terdapat pada campuran MPF-25\% yaitu $1.312 \mathrm{~kg} / \mathrm{m}^{3}$, sedangkan berat jenis tertinggi terdapat pada campuran MS- $15 \%$ yaitu sebesar $1.707 \mathrm{~kg} / \mathrm{m}^{3}$.

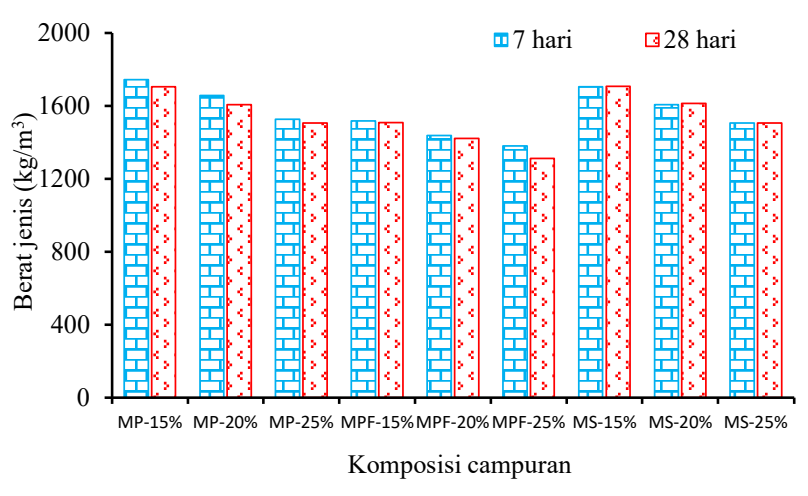

Gambar 2. Berat jenis mortar polimer epoxy resin

\section{Kuat Tekan}

Hasil pengujian kuat tekan mortar polimer epoxy resin dapat dilihat pada Gambar 3. Nilai kuat tekan maksimum mortar epoxy resin tanpa menggunakan fiberglass terdapat pada campuran MP-25\% sebesar 35,50 $\mathrm{MPa}$ dan kuat tekan minimum terdapat pada campuran MP-15\%, yaitu sebesar 12,49 Mpa .Nilai kuat tekan maksimum mortar epoxy resin dengan fiberglass adalah 25,55 MPa yang dihasilkan oleh campuran MPF-25\%, sedangkan kuat tekan minimum $15,70 \mathrm{MPa}$ dihasilkan oleh campuran MPF-15\%. Nilai kuat tekan yang didapat pada penelitian ini sesuai dengan hasil penelitian Prema, dkk. (2017) yang menyatakan bahwa semakin banyak kadar epoxy masuk ke dalam pori-pori, maka daya ikat semakin kuat.

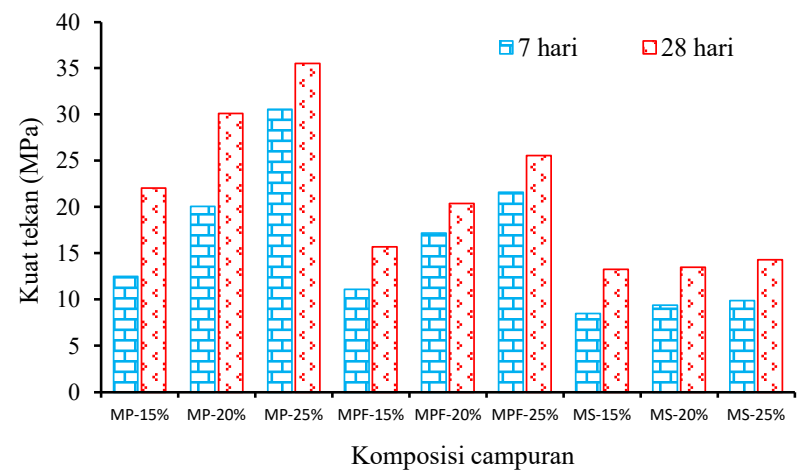

Gambar 3. Kuat tekan mortar polimer epoxy resin

\section{Kuat Lentur}

Gambar 4 menyajikan hasil pengujian kuat lentur mortar polimer epoxy resin. Nilai kuat lentur tertinggi pada mortar epoxy resin tanpa fiber terdapat pada campuran MP-25\% yaitu sebesar 7,11 MPa. Kuat tekan minimum campuran mortar epoxy resin tanpafiber terdapat pada campuran MP-15\%, yaitu sebesar 3,91 MPa. Nilai kuat lentur maksimum dan minimum pada mortar epoxy resin dengan fiberglass terdapat pada campuran MPF-25\% dan MPF-15\% yaitu masing-masing sebesar $8,00 \mathrm{MPa}$ 
dan 4,44 MPa. Nilai kuat lentur mortar epoxy resin menggunakan fiberglass lebih tinggi dibandingkan mortar epoxy resin tanpa fiberglass. Hal ini sesuai dengan hasil penelitian yang telah dilakukan oleh Jagarapu, dkk. (2016).

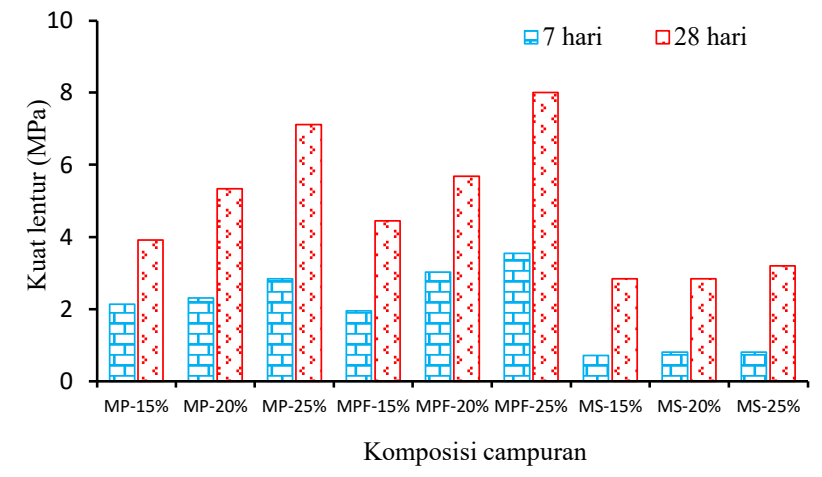

Gambar 4. Kuat lentur mortar polimer epoxy resin

\section{Hubungan Kuat Tekan dan Berat Jenis}

Hubungan berat jenis dan kuat tekan mortar epoxy resin disajikan pada Gambar 5. Hasil penelitian menunjukkan bahwa semakin tinggi kuat tekan, maka berat jenis semakin kecil. Sebaliknya, semakin rendah kuat tekan, maka berat jenis semakin tinggi. Hubungan berat jenis dan kuat tekan mortar polimer epoxy resin dinyatakan dengan persamaan 1:

$$
y=1.051 e^{-0,003 x}
$$

dengan:

$\mathrm{y}:$ kuat tekan $(\mathrm{MPa})$

$\mathrm{x}$ : berat jenis $\left(\mathrm{kg} / \mathrm{m}^{3}\right)$

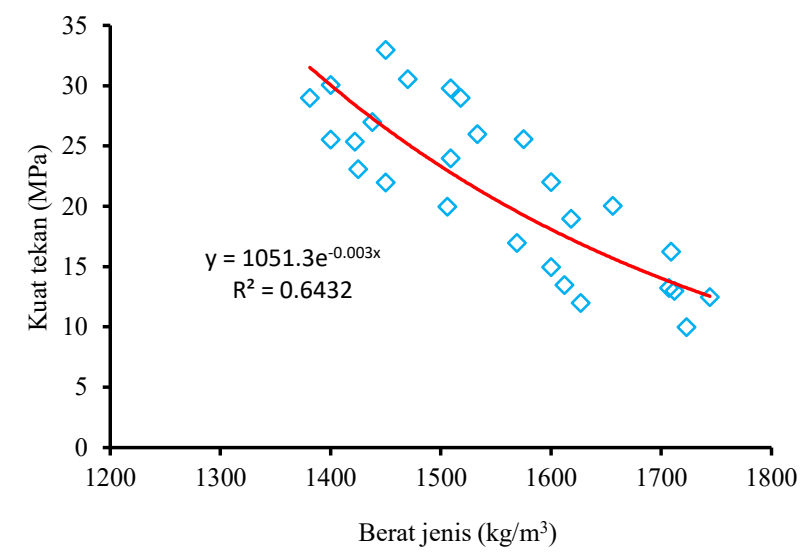

Gambar 5. Berat jenis vs kuat tekan mortar polimer epoxy resin

\section{Hubungan Kuat Tekan dan Kuat Lentur}

Hasil penelitian menunjukkan hubungan kuat tekan dan kuat lentur berbanding lurus seperti yang diperlihatkan pada Gambar 6. Semakin tinggi kuat lentur, maka kuat tekan semakin tinggi. Begitu pula sebaliknya, semakin rendah kuat lentur, maka kuat tekan semakin kecil. Hubungan kuat lentur dan kuat tekan mortar polimer epoxy resin dinyatakan pada Persamaan 2 sesuai dengan SNI 2847-2019 yaitu:

$$
y=11,27 \mathrm{e}^{0,1727 x}
$$

dengan:

$\mathrm{y}:$ kuat tekan $(\mathrm{MPa})$

$\mathrm{x}:$ kuat lentur $(\mathrm{MPa})$



Gambar 6. Kuat lentur vs kuat tekan mortar polimer epoxy resin

\section{Scanning Electron Microscopy (SEM)}

Karakterisasi mikrostruktur mortar polimer epoxy resin dan mortar normal menggunakan Scanning Electron Microscopy (SEM) dan bertujuan untuk mengetahui morfologi struktur komposit. Gambar 7 merepresentasikan mikrostruktur mortar polimer epoxy tanpa fiber dengan scale bar $10 \mu \mathrm{m}$. Pada Gambar 7 terlihat bahwa epoxy tidak mampu diikat dengan baik oleh matriks, sehingga banyak epoxy yang berkumpul di satu tempat dan menimbulkan pori (void) di tempat lain. Hal ini yang menyebabkan kekuatan mortar berkurang karena ketika mortar menerima beban, maka tegangan akan berpindah ke daerah void.

Gambar 8 merepresentasikan mikrostruktur mortar polimer epoxy resin dengan fiberglass scale bar $10 \mu \mathrm{m}$ yang memperlihatkan tidak adanya void dengan ukuran yang besar. Jumlah void tergantung pada jumlah fiber dan variasi epoxy yang digunakan, sehingga matriks mengikat agregat dengan baik. Epoxy resin dengan agregat halus menghasilkan kepadatan yang menyebabkan peningkatan kuat tekan mortar (Juanda, dkk., 2019).

Mikrostruktur mortar normal menggunakan semen disajikan pada Gambar 9 dengan scale bar $10 \mu \mathrm{m}$. Terlihat bahwa matriks dan agregat tidak berikatan dengan baik. Hal ini ditunjukkan pada interface antara matriks dan agregat yang tidak beraturan. Selain itu, kandungan semen tidak terdistribusi baik dengan matriks. Akibatnya muncul void yang menurunkan kekuatan mortar. Ketika mortar menerima beban, maka tegangan akan berpindah ke daerah void. 
Cantilever $\mid$ Volume: 10 Nomor: 2 | Oktober 2021 | ISSN: 1907-4247 (Print) $\mid$ ISSN: 2477-4863 (Online) | Website: http://cantilever.id Bambang Utomo, dkk. | Karakteristik Mortar Polimer Epoxy Resin Dengan Fiberglass

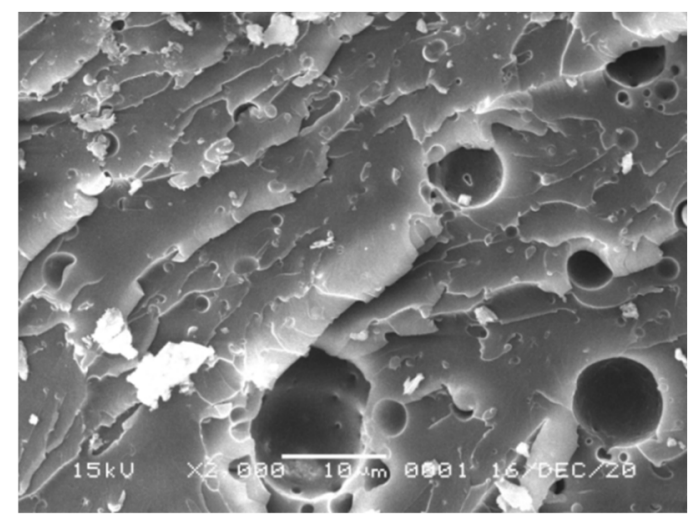

Gambar 7. Mikrostruktur mortar polimer epoxy resin tanpa fiberglass

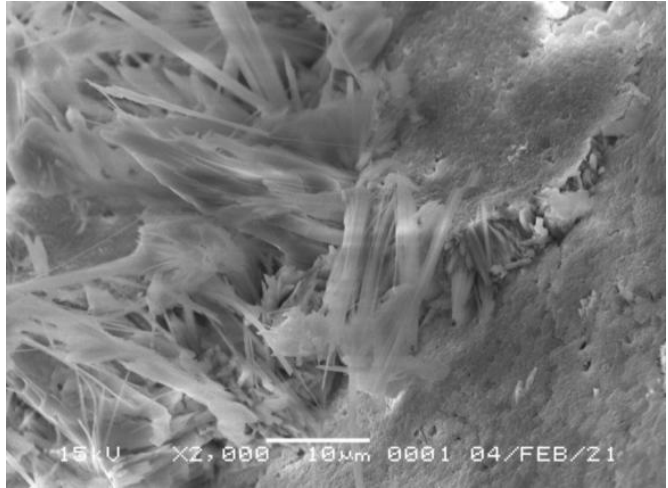

Gambar 8. Mikrostruktur mortar polimer epoxy resin dengan fiberglass



Gambar 9. Mikrostruktur mortar normal dengan semen

\section{KESIMPULAN}

Kesimpulan hasil penelitian adalah uji massa jenis menunjukkan bahwa benda uji yang menggunakan fiberglass menyebabkan nilai kerapatan menjadi lebih rendah. Komposisi optimum campuran mortar polimer terdapat pada campuran MP- $25 \%$. Pada benda uji yang menggunakan fiberglass dan tanpa fiberglass, semakin tinggi umur benda uji, maka semakin rendah nilai kerapatannya.

Hasil pengujian kuat tekan menunjukkan bahwa variasi mortar epoxy resin dengan agregat halus menghasilkan kepadatan yang menyebabkan peningkatan kuat tekan mortar dibanding hasil kuat tekan pada variasi semen (Juanda, dkk., 2019).

Mortar yang menggunakan bahan fiberglass akan menyebabkan nilai kuat tekan menjadi lebih rendah. Sebaliknya, penggunaan fiberglass di dalam campuran epoxy resin pada spesimen yang diuji kuat tekan, hasil tersebut berbanding lurus sama hasil penelitian (Durga, 2016) bisa dilihat hasil uji kuat tekan variasi fiber lebih rendah dari hasil variasi non fiber pada benda uji dengan kadar fiber glass sebesar 3\% dengan hasil kuat tekan sebesar 26,11 MPa.

Uji kuat lentur dan uji SEM pada variasi fiberglass menghasilkan kinerja yang lebih optimum dibandingkan campuran normal yang menggunakan campuran semen karena fiberglass dapat menahan terjadinya suatu crack atau lebih meluas.

\section{SARAN}

Terdapat beberapa saran untuk penelitian yang akan datang, yaitu pengujian sifat mekanik mortar meliputi uji kuat tarik belah dan kuat lentur. Pada agregat halus perlu dilakukan pengujian SEM, XRF, dan XRD sebelum digunakan dalam pembuatan beton untuk mengetahui mikrostruktur dan kandungan mineralnya.

\section{REFERENSI}

American Society for Testing and Materials.(2017). ASTM C29 / C29M - 17aStandard Test Method for Bulk Density ("Unit Weight”) and Voids in Aggregate, West Conshohocken, Pennsylvania, United States.

American Society for Testing and Materials. (2020). ASTM C40 / C40M - 20Standard Test Method for Organic Impurities in Fine Aggregates for Concrete, West Conshohocken, Pennsylvania, United States.

American Society for Testing and Materials.(2015). ASTM ASTM C128 - 15Standard Test Method for Relative Density (Specific Gravity) and Absorption of Fine Aggregate, West Conshohocken, Pennsylvania, United States.

American Society for Testing and Materials. (2019). ASTM C136 / C136M - 19Standard Test Method for Sieve Analysis of Fine and Coarse Aggregates, West Conshohocken, Pennsylvania, United States.

American Society for Testing and Materials.(2017). ASTM C142 / C142M - 17Standard Test Method for Clay Lumps and Friable Particles in Aggregates, West Conshohocken, Pennsylvania, United States.

American Society for Testing and Materials. (2017). ASTM C172 / C172M - 17 Standard Practice for Sampling Freshly Mixed Concrete, West Conshohocken, Pennsylvania, United States.

American Society for Testing and Materials. (2014). ASTM D2419 - 14 Standard Test Method for Sand Equivalent Value of Soils and Fine Aggregate, West Conshohocken, Pennsylvania, United States.

American Society for Testing and Materials.(2019). ASTM C566 - 19Standard Test Method for Total Evaporable Moisture Content of Aggregate by Drying, West Conshohocken, Pennsylvania, United States. 
Bowo, A. F., Saloma,Nurjannah,S.A., dan Juliantina, I.,(2020).Sulfate Resistance Of Polymer Light-Weight Concrete with Variation of Epoxy Resin, International Journalof Scientific\& Technology Research, Vol. 9 (5), 4549.

Deshmukh, S. H., Bhusari, J. P., dan Zende, A. M.(2012). Effect of Glass Fibres on Ordinary Portland Cemend Concrete, Journal of Engineering, Vol. 2 (6), 1318-1322.

Gowri, R. dan Angeline, M. M. (2013). Effect of Glass Wool Fibres on Mechanical Properties of Concrete.International Journal of Engineering Trends and Technology, Vol. 4 (7), 2231-538.

Jagarapu, D. C. K., Abhilash, G.V.S., Khasim, K. P., dan Manikanta, S.G. (2016). Experimental Studies on Glass Fiber Concrete, American Journal of Engineering. Vol. 5 (5), 100-104.

Juanda, O., Sagraff, A., Saloma, dan Hanafiah. (2019). Physical and Mechanical Properties of Lightweight Polymer Concrete with Epoxy Resin,International Journalof Scientific\& Technology Research,Vol. 8 (7), 857-863.

Kumar, G. B. R. dan Venkatesh, B. (2018). Experimetal Study on Polymer Concrete with Epoxy Resin, International Journal of Pure and Applied Mathematics, Vol. 119 (17), 3129-3138.

Pimplikar, S. S., and Shakor, P. N.(2011).Glass Fiber Reinforced Concrete Composites, International Journal of Technology and Engineering System, Vol. 2 (2), 632-634.

Prema, S., Sakthivel, S., Sankar, C., Kumar, J.V., dan Vijay. S. (2017). Comparative Study on Polymer Resin Concrete, International Journal of ChemTech Research, Vol. 10 (8), 656-661.

Ravikumar, C.S.,Ramasamy, V., dan Thandavamoorthy, T.S. (2015). Effect ofFibers in Concrete, International Journal ofApplied Engineering Research, Vol. 10 (1), 419-430.

Yemam, D. M., Kim, B. J., Moon, J. Y., dan Yi, C., (2017). Mechanical Properties of Epoxy Resin Mortar with Sand Washing Waste as Filler, Materials, Vol. 10 (3), 1003-246. 